\section{El peligro del carbunco: características y tratamiento de la infección}

El agente causal del carbunco, enfermedad conocida por anthrax en ingles, es un bacilo grampositivo grande de metabolismo aerobio conocido por Bacillus anthracis. In vitro forma largas cadenas, pero in vivo se observa en forma de organismos aislados o en cadenas muy cortas. Cuando el medio no provee las sustancias necesarias para su sustento, forma esporas que pueden sobrevivir en la tierra por varios decenios. Normalmente no se forman esporas en los tejidos del huésped a no ser que los líquidos corporales infectados se vean expuestos al ambiente.

La virulencia de $B$. anthracis se debe a dos factores principales: una cápsula que impide la fagocitosis de las formas vegetativas, y dos exotoxinas binarias, ambas dotadas de una proteína B (de fijación) que le permite a la bacteria penetrar en la célula. $\mathrm{La}$ toxina productora de edema contiene, además, una proteína A (de actividad enzimática) que provoca una reacción edematosa intensa en el sitio por donde penetra la bacteria, inhibe la función de los neutrófilos y altera la producción de sustancias quimiotácticas. En el caso de la segunda toxina, conocida por toxina letal, la proteína A inhibe la transmisión de señales intracelulares. Esta toxina estimula la liberación del factor $\alpha$ de necrosis tumoral y de interleucina $1 \beta$, lo cual parece contribuir al fenómeno de muerte súbita por toxicidad.

La infección se produce cuando una espora penetra en la piel por una herida (carbunco cutáneo) o por la mucosa del aparato digestivo (carbunco gastrointestinal), o bien cuando hay inhalación de esporas. Después de la ingestión por macrófagos en el sitio de penetración, la bacteria adopta la forma vegetativa y procede a proliferar en los espacios extracelulares y a producir la cápsula y las toxinas. Cuando se inhalan esporas, estas se depositan en los espacios alveolares. De ahí son transportadas a los nódulos mediastínicos, donde germinan en un período de 60 días. Según datos obtenidos de primates, el carbunco suele ser letal para el ser humano cuando la inhalación es de 2500 a 55000 esporas.

Más de $95 \%$ de los casos de carbunco que ocurren en el mundo son de la forma cutánea. De uno a siete días después de la penetración de la bacteria por una ruptura en la piel, se produce una lesión papulosa prurítica pero no dolorosa, seguida al poco tiempo de un brote de vesículas pequeñas alrededor de la lesión inicial, o bien de una sola vesícula más grande que contiene líquido serosanguinolento y grandes cantidades de bacterias. Alrededor de la lesión se produce un edema fluctuante y pronunciado y puede haber febrícula y malestar general. La vesícula a la larga se rompe, se necrotiza y forma una úlcera grande cubierta de una escara negruzca. Es importante evitar el desbridamiento o la incisión de estas lesiones tempranas, que solo aumentaría el riesgo de una bacteriemia. A las dos semanas aproximadamente o antes, la escara se seca y se desprende, dejando poca cicatriz. Al principio se observa una linfadenopatía regional. En ocasiones, se produce una sobreinfección por Staphylococcus aureus o por estreptococos cuyos síntomas suelen ser fiebre, dolor local, linfangitis y supuración. La bacteriemia es una complicación poco frecuente y se puede acompañar de meningitis. Sin la administración de antibióticos, la mortalidad asciende a $20 \%$.

El carbunco gastrointestinal se produce de dos a cinco días depués de la deglución de carnes mal cocidas con esporas y se manifiesta con náuseas, vómitos, fiebre y dolor abdominal. Poco después se destapa un cuadro diarreico sanguinolento con dolor abdominal agudo como consecuencia de las ulceraciones en el íleo terminal o el ciego. Si se forman úlceras gástricas, puede haber hematemesis. En ocasiones se produce una linfadenitis mesentérica hemorrágica con ascitis. La mortalidad asciende a más de $50 \%$.

La forma más peligrosa de carbunco es la que se produce por inhalación. Se caracteriza por linfadenitis y mediastinitis hemorrágica en la región torácica y, en una elevada fracción de los casos, por una lesión pulmonar localizada y necrótica. La dolencia es bifásica. En su fase inicial, que ocurre tras un período de incubación de uno a seis días, la enfermedad produce fiebre, malestar, mialgias, tos seca y dolor torácico o abdominal. A los dos o tres días comienza súbitamente la segunda fase, de comienza súbito, en la que hay fiebre más alta, disnea aguda, diaforesis y cianosis. El agrandamiento de los nódulos mediastínicos produce obstrucción de la traquea, que se ve empeorada por el ensanchamiento del mediastino y por edema subcutáneo en el pecho y el cuello. En alrededor de la mitad de los pacientes se producen síntomas de meningitis. En su segunda fase la enfermedad empeora acelerada- 
mente; se producen choque e hipotermia y el paciente muere en 24 a 36 horas.

El diagnóstico de carbunco se hace por observación directa de los bacilos grampositivos anchos y encapsulados en muestras de líquido vesicular, líquido cefalorraquídeo o sangre. También puede hacerse por cultivo en placas de agar sangre, ya que el bacilo no prolifera en el medio de MacConkey. El hisopado nasal para determinar si ha habido inhalación de esporas de B. anthracis es una herramienta de investigación poco apropiada para pronosticar con precisión el riesgo de enfermedad sintomática.

Las pruebas serológicas solo tienen valor retrospectivamente, en la fase de convalecencia, cuando se pueden comparar los resultados con los obtenidos en la fase aguda. En casos de carbunco cutáneo y orofaríngeo, se detectan anticuerpos al antígeno protector o a la cápsula por medio de inmunoensayo enzimático (ELISA). Estas pruebas son especialmente útiles para confirmar el diagnóstico cuando los cultivos no muestran ningún microorganismo. No tendría utilidad efectuar pruebas serológicas a los contactos recientes de los casos confirmados, ya que habría que hacerles una segunda prueba semanas más tarde en la fase de convalecencia para hacer el diagnóstico serológico.

No se debe administrar ningún tratamiento antimicrobiano a personas asintomáticas a no ser que las autoridades sanitarias hayan determinado que hay un riesgo patente de exposición a $B$. anthracis. De hecho, el uso innecesario de antibióticos por un período prolongado puede dar lugar a la selección de cepas resistentes. Cuando es necesaria, la profilaxis debe administrarse durante mucho tiempo, dado el largo tiempo que suele transcurrir entre la inhalación de esporas y su germinación.

Ante la amenaza de un ataque terrorista y en vista de que una cepa de $B$. anthracis resistente a muchos antibióticos (penicilina, doxiciclina, cloramfenicol, macrólidos y rifampicina) ha sido cultivada con este fin, la profilaxis inicial de elección en adultos que han sufrido algún tipo de exposición consiste en ciprofloxacino, administrado a dosis orales de $500 \mathrm{mg}$ cada 12 horas. En niños, la dosis debe ser de 10 a $15 \mathrm{mg}$ por $\mathrm{kg}$ de peso corporal cada 12 horas. También puede usarse la doxiciclina a una dosis oral, en adultos o niños que pesen más de 45 $\mathrm{kg}$, de $100 \mathrm{mg}$ dos veces al día. El tratamiento óptimo, una vez confirmada la susceptibilidad del micoorganismo, es la amoxicilina, administrada oralmente en dosis de $500 \mathrm{mg}$ cada 8 horas en adultos y niños de más de $20 \mathrm{~kg}$ de peso. En niños con un peso menor, la dosis diaria recomendada es de 40 $\mathrm{mg}$ por $\mathrm{kg}$ de peso corporal dividida en tres dosis (una cada 8 horas). El tratamiento debe tener una duración total de no menos de 60 días.
Hay una vacuna contra el carbunco, preparada a partir de un filtrado derivado de una cepa atenuada de $B$. anthracis, que se viene administrando a las fuerzas armadas estadounidenses desde 1998 a las semanas 0,2 y 4 y posteriormente a los 6 , 12 y 18 meses. Se necesita una dosis de refuerzo anual para mantener la inmunidad, pero la eficacia, según estudios en primates, ha sido confirmada. No parece acompañarse de efectos adversos importantes. Actualmente se dispone de muy poca vacuna, pero si en algún momento su distribución aumentara, podría significar la posibilidad de acortar el tratamiento profiláctico con antibióticos.

En casos de carbunco sintomático por inhalación de esporas, los Centros para el Control y la Prevención de Enfermedades (CDC, Atlanta, Estados Unidos) recomiendan un tratamiento inicial combinado a base de ciprofloxacino a una dosis intravenosa de $400 \mathrm{mg}$ cada 12 horas en adultos (en niños, un total diario de 20 a $30 \mathrm{mg} / \mathrm{kg}$ de peso corporal, dividido en dos dosis), más penicilina, que debe administrarse a dosis de 4 millones de unidades por vía intravenosa cada 4 horas en adultos y niños mayores de 11 años, y de 50000 unidades por $\mathrm{kg}$ de peso corporal cada 6 horas en niños menores de 12 años. Nuevamente, el tratamiento debe durar no menos de 60 días en total. Este tratamiento combinado, producto de una revisión reciente de los CDC (26 de octubre de 2001), obedece a la necesidad de proteger al paciente contra la posibilidad de una meningitis, cuya aparición suele ser súbita. Por otra parte, algunas cepas de B. anthracis detectadas en la Florida, Nueva York y Washington, D.C., han mostrado la presencia de lactamasas beta; por consiguiente, el tratamiento del carbunco sistémico con penicilina $G$, ampicilina o amoxicilina únicamente no se recomienda. En el caso de grupos particularmente vulnerables, como las mujeres embarazadas, los pacientes inmunodeprimidos y los niños, hay recomendaciones terapéuticas más detalladas (JAMA 1999;281:1735-45).

En el caso de las cepas que ocurren en la naturaleza, la penicilina siempre se ha mostrado eficaz, con escasa resistencia. In vitro, B. anthracis también muestra susceptibilidad a los antimicrobianos más comunes. La resistencia observada hasta ahora ha sido principalmente a la cefuroxima, cefalosporinas de amplio espectro (cefotaxima y ceftazidima), aztreonam, trimetoprima y sulfametoxazol.

Ya que no se ha documentado la transmisión del carbunco de una persona a otra, aun en el caso de pacientes con enfermedad por inhalación no hay necesidad de aislar a los pacientes hospitalizados. Para la descontaminación se han de utilizar soluciones esporicidas a base de lejía. Los CDC han emitido información al respecto que puede consultarse 
en http://www.bt.cdc.gov. (Swartz MN. Recognition and management of anthrax - an update. JAMA 2001;345(22).)

\section{La exposición del agua al sol protege contra el peligro del cólera}

En un artículo que se publicó en 1996, Conroy et al. describieron los resultados de un ensayo de campo aleatorizado en el que se investigó la posibilidad de desinfectar el agua de consumo mediante su exposición al sol. El estudio, que se llevó a cabo en 1996 en el África subsahariana en una muestra de 206 niños de 5 a 15 años de edad, mostró una reducción de $10 \%$ de la incidencia de episodios de diarrea en los hijos de madres que guardaban el agua de consumo en recipientes transparentes en el techo de la casa, al ser comparados con los de madres que guardaban el agua adentro. En el primer grupo también se observó una reducción de $24 \%$ de la incidencia de casos de diarrea grave en comparación con el segundo. Posteriormente, el estudio se extendió para abarcar a los niños menores de 6 años, y a fines de 1997 y comienzos de 1998, a raíz de un período de lluvias e inundaciones, en la zona se produjo un brote de cólera que afectó a niños y adultos. Esto brindó una oportunidad de estudiar el efecto protector de la exposición del agua de consumo al sol, ya que todas las familias que habían participado en el ensayo anterior seguían practicando la desinfección solar.

Seis semanas después del brote, un investigador que hablaba bien el idioma local o uno de los trabajadores de salud locales procedieron a visitar cada uno de los hogares del estudio original y a entrevistar, en su propio idioma, a las madres o abuelas. Sobre la base de cuatro criterios clínicos fácilmente reconocibles por la población local y los síntomas descritos por los entrevistados, determinaron el número de casos de la enfermedad en menores de 6 años que se habían producido en el grupo de estudio (155) y el grupo testigo (144) durante el brote.

Los resultados no revelaron ninguna diferencia significativa entre un grupo y otro en el número de casos de cólera en adultos o niños mayores. No obstante, de los 155 niños menores de 6 años que integraban el grupo de estudio, solamente tres tuvieron una enfermedad compatible con el cólera. En cambio, de los 144 niños del grupo testigo, 11 padecieron la enfermedad (razón de posibilidades [OR]: 0,12; IC95\%: 0,02 a 0,65; $P=0,014$ ). (Conroy RM, Meegan ME, Joyce T, McGuigan K, Barnes J. Solar disinfection of drinking water protects against cholera in children under 6 years of age. Arch Dis Child 2001;85(4):293-295.)

\section{Las placas de amiloide no necesariamente explican la demencia en la enfermedad de Alzheimer}

El rasgo principal de la enfermedad de Alzheimer es la pérdida de la memoria, que se manifiesta en su fase más temprana, antes de que se presenten alteraciones cognoscitivas de otra índole. El diagnóstico definitivo de la enfermedad se hace por examen histológico posmortem del tejido cerebral, que revela las clásicas placas de amiloide y nudos neurofibrilares. En estudios con ratones que han tenido mutaciones en el gen de la proteína precursora del amiloide (PPA) beta se ha observado cierta correlación entre algunos de los déficit cognoscitivos y la acumulación de placas de amiloide durante el envejecimiento. Asimismo, otros estudios en animales han mostrado que la reducción de las placas de amiloide en el cerebro mediante la aplicación de una vacuna mejora algunos déficit del aprendizaje, lo cual parecería corroborar que estas placas, y por ende la PPA, contribuyen, de hecho, a la sintomatología de la enfermedad de Alzheimer.

Lo que no se sabe a ciencia cierta es si hay correlación directa entre la pérdida de la memoria y las placas de amiloide, o si la forma disoluble de la proteína o la forma fibrilar (la que se encuentra en las placas) es la responsable de la pérdida de la memoria. En experimentos recientes, un grupo de investigadores ha buscado una correlación usando ratones transgénicos cuyas neuronas contienen un isómero de la PPA. Estos ratones muestran rasgos histopatológicos tempranos de la enfermedad de Alzheimer y forman depósitos difusos de amiloide beta, pero no forman placas amiloideas. No obstante, los investigadores detectaron en ellos algunas alteraciones cognoscitivas y de la memoria, lo cual es un indicio de que la formación de placas de amiloide no es condición necesaria para que la memoria sufra deterioro. La conclusión es que este último fenómeno podría obedecer a una simple elevación de la PPA beta, a una sobreexpresión neuronal de la forma isomérica de la proteína, a un aumento del amiloide beta disoluble o a la presencia de péptidos intracelulares.

En resumen, los resultados de este estudio confirman que una leve sobreexpresión de la PPA beta en las neuronas provoca una alteración progresiva de la memoria que aumenta con la edad, independientemente de la formación de placas neuríticas amiloideas. (Koistinaho $\mathrm{M}$, Ort $\mathrm{M}$, Cimadevilla JM, Vondrous R, Cordell B, Koistinaho J, et al. Specific spatial learning deficits become severe with age in beta-amyloid precursor protein transgenic mice that harbor diffuse beta-amyloid deposits but do not form plaques. Proc Natl Acad Sci USA 2001; 
(publicación electrónica el 27 de noviembre, antes de la publicación impresa.)

\section{La infección por VIH favorece la transmisión sexual del virus de la hepatitis $C$}

El virus de la hepatitis C (VHC), el agente etiológico de la mayoría de las hepatopatías crónicas, se transmite habitualmente por vía parenteral, sobre todo por transfusiones de sangre o consumo de drogas intravenosas. Sin embargo, en una considerable proporción de casos no se identifican factores de riesgo parenterales, lo cual sugiere la existencia de otras vías de transmisión. Los datos acerca de la posible transmisión sexual del VHC son contradictorios. La coinfección por VHC es frecuente en pacientes infectados por el virus de la inmunodeficiencia humana (VIH) (20 a 65\%), especialmente en los receptores de transfusiones de sangre y en los adictos a drogas por vía parenteral (80 a 90\%). La prevalencia también es alta en los varones homosexuales ( 8 a $15 \%)$ y algunos informes señalan una elevada tasa de transmisión sexual del VHC en las parejas de los individuos con anticuerpos anti-VIH. Con el fin de investigar el papel de la infección por VIH en la transmisión sexual del VHC, en este estudio de casos y controles se determinó la prevalencia de anticuerpos anti-VHC en función de la presencia o ausencia de infección por VIH en individuos con contactos heterosexuales $u$ homosexuales y sin antecedentes de consumo de drogas intravenosas ni de transfusiones sanguíneas.

El estudio se realizó en pacientes del área de Nápoles, Italia, con infección por VIH o con riesgo de adquirirla y cuyo comportamiento sexual los ponía en riesgo de adquirir infecciones transmitidas por vía parenteral. Los casos fueron todos los pacientes ambulatorios observados entre noviembre de 1994 y noviembre de 1999 que eran positivos para el VIH. Por cada caso se seleccionaron dos controles observados en el mismo centro durante el mismo período de tiempo y en los cuales los resultados de las pruebas de anticuerpos anti-VIH fueron negativos. Los casos y los controles fueron apareados por edad ( \pm 5 años), sexo y factores de riesgo de infecciones transmitidas por vía parenteral. Cada participante rellenó un cuestionario sobre los datos demográficos, los antecedentes de consumo de drogas y transfusiones de sangre, los comportamientos sexuales, el tipo de relaciones sexuales y el riesgo de exposición a infecciones transmitidas por vía parenteral. Se excluyeron todos los individuos con antecedentes de consumo de drogas intravenosas o transfusiones de sangre y solo se incluyeron aquellos con exposición homosexual o heterosexual a infecciones transmitidas por vía parenteral. Se ob- tuvieron muestras de suero para detectar anticuerpos anti-VIH y anti-VHC y marcadores del virus de la hepatitis B (HBsAg y HBcAb). El análisis estadístico de los resultados se realizó con las pruebas de la $t$ y de la $\chi^{2}$; se consideraron significativos los valores de $P<0,05$.

Participaron 106 casos (61 hombres y 45 mujeres) con una mediana de 32 años (17 a 55) y 212 controles (122 hombres y 90 mujeres) con una mediana de 30 años (17 a 56). Con respecto a los factores de riesgo, de los 106 casos, 37 (34,9\%) tuvieron relaciones heterosexuales peligrosas; $32(30,2 \%)$, relaciones homosexuales masculinas sin protección; 5 $(4,7 \%)$, relaciones heterosexuales con drogadictos; $31(29,2 \%)$, relaciones heterosexuales con una pareja estable que era seropositiva para el VIH, y $1(0,9 \%)$, relaciones homosexuales masculinas con una pareja estable que era seropositiva para el VIH. En el grupo de control, las cifras correspondientes fueron $74(34,9 \%), 64(30,2 \%), 10(4,7 \%), 62(29,2 \%)$ y 2 $(0,9 \%)$, respectivamente. Esto es, los porcentajes fueron idénticos a los registrados en los casos.

La prevalencia de la positividad del HBsAg fue similar en los dos grupos $(4,7 \%$ en los casos y $2,4 \%$ en los controles) y no se observaron diferencias en función de los factores de riesgo sexuales. La presencia de anticuerpos anti-HBc en individuos con HBsAg negativo fue más frecuente en los casos $(33,9 \%)$ que en los controles $(15,6 \%)$. Esta diferencia se observó en todos los subgrupos de riesgo por contacto sexual, pero solo fue estadísticamente significativa en el subgrupo con actividad heterosexual peligrosa $(43,2 \%$ frente a $16,2 \%)$.

La presencia de anticuerpos anti-VHC fue más frecuente en los casos que en los controles $(15,1 \%$ frente a $5,2 \%)$ en todos los subgrupos de riesgo por contacto sexual. En los individuos con relaciones heterosexuales $\mathrm{u}$ homosexuales con parejas estables seropositivas para el VIH, la diferencia fue del 18,7\% frente al 1,6\%; en aquellos con relaciones heterosexuales peligrosas, del 10,8\% frente al 2,7\% (no significativa); en los hombres con relaciones homosexuales, del 15,6\% frente al 12,5\% (no significativa), y en los individuos con relaciones heterosexuales con drogadictos, del 20\% (1 de 5) frente al $0 \%$ (0 de 10$)$.

Este estudio demuestra que, en individuos cuya exposición a las infecciones transmitidas por vía parenteral ha sido exclusivamente sexual, la prevalencia de la infección por VHC es mayor en los coinfectados por el VIH que en los no coinfectados. Esto indica que el VIH puede aumentar la transmisión sexual del VHC, aunque no se puede excluir la contribución de factores de confusión como las intervenciones quirúrgicas o el hecho de compartir cepillos de dientes, maquinillas de afeitar o jeringas no desechables. De cualquier forma, estos 
factores deberían estar presentes tanto en los casos como en los controles. Independientemente de la presencia o ausencia de infección por VIH, la prevalencia de la infección por VHC fue alta en los hombres con relaciones homosexuales peligrosas, lo cual señala la mayor importancia de la transmisión homosexual de la infección por VHC. De hecho, en el Reino Unido se ha detectado una mayor seroprevalencia del VHC en los homosexuales $(8,9 \%)$ que en los heterosexuales $(1,1 \%)$. En cambio, las relaciones sexuales peligrosas y las relaciones homosexuales o heterosexuales sin protección con parejas estables seropositivas para el VIH se asociaron con una mayor prevalencia de la infección por VHC en los individuos coinfectados por el VIH. Aunque los estudios sobre la transmisión sexual del VHC no son concluyentes debido a la ausencia de control de los factores de confusión, estos estudios indican que dicha transmisión puede ocurrir, aunque parece ser menor que en el caso del VIH o del virus de la hepatitis B.

En resumen, de acuerdo con los resultados de este estudio y de otros anteriores, se puede concluir que la transmisión sexual del VIH es rara en la población general, pero que la coinfección por el VIH contribuye a aumentarla, probablemente debido a que la inmunodepresión favorece la replicación del VHC. (Filippini P, Coppola N, Scolastico C, Rossi G, Onofrio M, Sagnelli E, et al. Does HIV infection favor the sexual transmission of hepatitis C? Sex Transm Dis 2001;28:725-729.)

\section{Repercusiones de la obesidad en la infancia sobre la salud en la edad adulta}

La obesidad infantil está en aumento y preocupa el hecho de que pueda incrementar el riesgo de morbilidad en la edad adulta. El índice de masa corporal (IMC) en la infancia se ha correlacionado de forma significativa con el IMC en la edad adulta y se ha verificado que los adultos que fueron obesos en la infancia tienen mayor mortalidad por todas las causas. No obstante, todavía no se han esclarecido totalmente las repercusiones a largo plazo de la obesidad infantil. El objetivo de este estudio consistió en determinar si el sobrepeso en la infancia se asocia con un aumento de los riesgos para la salud en la edad adulta y en qué medida se puede atribuir dicho aumento del riesgo a la tendencia de los niños obesos a ser adultos obesos.

Para ello se utilizaron los datos del Estudio de Mil Familias de Newcastle, un estudio prospectivo de 1142 sujetos reclutados al nacer, en mayo y junio de 1947, en la ciudad de Newcastle, Reino Unido. Dos tercios de la cohorte fueron seguidos hasta los 15 años de edad. En los años noventa se identifica- ron los participantes a través del registro central del Sistema Nacional de Salud del Reino Unido y se codificaron sus causas de muerte. A partir de los registros del estudio original se obtuvieron los datos sobre el desarrollo fetal, la lactancia y la infancia, entre ellos el peso al nacer, la edad gestacional, la ocupación del padre en 1947 y los pesos y tallas registrados durante la infancia. Mediante un cuestionario realizado en 1996-1998, se obtuvieron datos sobre el estilo de vida, el peso, la talla y las enfermedades en la edad adulta; durante este mismo período se realizó un examen clínico en el que se determinaron varios marcadores de riesgo biológico: grosor de la media y la íntima de la carótida, determinado por ecografía; tensión arterial; concentraciones plasmáticas de fibrinógeno, colesterol total y colesterol de las lipoproteínas de baja y alta densidad, triglicéridos, insulina y glucosa; peso, talla y perímetro de la cintura, y porcentaje de grasa corporal, determinado mediante impedanciometría.

De los 1142 niños de la cohorte original, 932 fueron seguidos hasta el final del primer año de vida y 47 de ellos fallecieron después de los 18 años. En 688 participantes se efectuaron mediciones a los 9 años de edad, y en 628 se repitieron a los 13 años. En el examen clínico realizado a la edad aproximada de 50 años participaron 412 individuos (44\%), y en 529 había datos sobre el peso y la talla a esta edad.

El IMC en la infancia mostró una correlación moderadamente significativa con el IMC en la edad adulta (a los 9 años: $r=0,24, P<0,001$; a los 13 años: $r=0,39, P<0,001)$. Los individuos cuyo IMC era superior al percentil 90 a los 9 o a los 13 años tenían una probabilidad cinco a nueve veces mayor de ser obesos a los 50 años, en comparación con aquellos cuyo IMC se encontraba en el cuartil inferior. La asociación entre el IMC en la infancia y el porcentaje de grasa corporal en la edad adulta fue más débil que la registrada con respecto al IMC en la edad adulta (a los 9 años: $r=0,1, P=0,07$; a los 13 años: $r=0,22, P<0,001)$.

En el análisis univariado, el IMC y el porcentaje de grasa corporal a los 50 años estaban fuertemente asociados con la mayoría de los factores de riesgo de enfermedad en la edad adulta. Después de controlar los efectos del IMC en la edad adulta, el IMC en la infancia presentó asociaciones inversas con los factores de riesgo de enfermedad en adultos. En las mujeres, el IMC a los 9 años se asoció de forma significativa con las concentraciones de triglicéridos, insulina, glucosa y colesterol total, así como con la tensión arterial diastólica y sistólica; a los 13 años solo se asoció significativamente con las concentraciones de triglicéridos, insulina y glucosa. En los hombres, el IMC a los 9 años se asoció de forma significativa con las concentraciones de tri- 
glicéridos, insulina y glucosa, mientras que a los 13 solo se asoció con la insulinemia en ayunas.

Después de controlar los efectos del porcentaje de grasa corporal en la edad adulta, en vez de los efectos del IMC a esta misma edad, las relaciones entre el IMC en la infancia y la insulinemia y la glucemia se atenuaron mucho en las mujeres y prácticamente desaparecieron en los hombres; las asociaciones entre el IMC en la infancia y la tensión arterial en la edad adulta también tendieron a desaparecer.

Los 47 individuos que fallecieron en la edad adulta y los 20 que cumplieron los criterios de síndrome metabólico no presentaron mayores probabilidades que los demás de haberse encontrado en el cuartil superior de la distribución del IMC a los 9 ni a los 13 años.

Aunque los adolescentes con sobrepeso tenían mayor tendencia a ser adultos obesos, la mayoría de los adultos obesos no habían tenido sobrepeso en la infancia y los individuos delgados en la infancia y la adolescencia no se encontraban protegidos frente a la obesidad en la edad adulta. Por otra parte, se comprobó que los individuos delga- dos en la infancia eran los que tenían mayor riesgo global de enfermedad en la edad adulta.

De acuerdo con los resultados de este estudio: 1) el sobrepeso en la infancia no se asoció con un aumento de los riesgos para la salud en la edad adulta; 2) el IMC en la infancia estaba relacionado con el IMC, pero no con el porcentaje de grasa corporal, en la edad adulta; 3) únicamente los niños obesos a los 13 años presentaron un mayor riesgo de ser adultos obesos, y 4) los individuos más delgados en la infancia y más gordos en la edad adulta fueron los que corrieron mayor riesgo de enfermedad en la edad adulta. Esto lleva a los autores a concluir que las intervenciones poblacionales dirigidas a reducir el IMC en la infancia podrían no proporcionar beneficios en la edad adulta. En cambio, el peso inferior al normal en la infancia sigue siendo preocupante, dado que no confiere protección frente a la obesidad en la edad adulta y se asocia con un aumento del riesgo de enfermedad a esta edad. (Wright CM, Parker L, Lamont D, Craft AW. Implications of childhood obesity for adult health: findings from thousand families cohort study. BMJ 2001;323:1280-1284.)

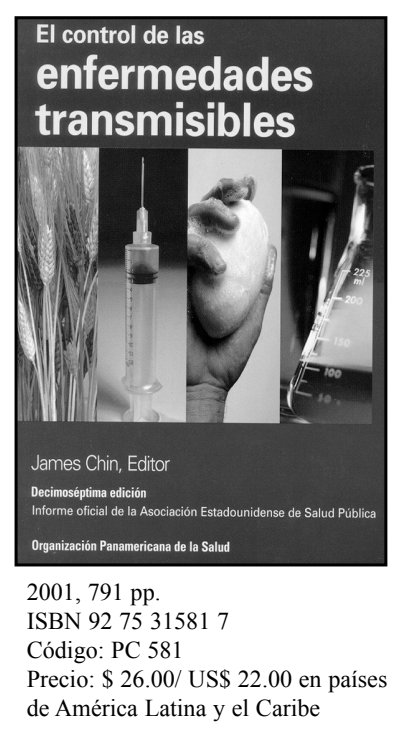

\section{El control de las enfermedades transmisibles, $17 .^{a}$ ed.}

Este libro es una obra de consulta ampliamente conocida sobre las enfermedades transmisibles. Fácil de entender y de usar, contiene información sobre más de trescientas enfermedades. En su decimoséptima edición se han revisado de forma exhaustiva todas las enfermedades comprendidas en la edición anterior y se ha actualizado casi un tercio; se presenta también material adicional sobre las enfermedades víricas por Hendra y Nipah. Además, la obra ha sido ampliada con una nueva sección sobre la respuesta de los trabajadores de la salud pública al bioterrorismo.

El libro es una referencia sumamente útil, si no indispensable, para todos los profesionales de la salud, en especial para quienes necesitan una obra práctica de consulta rápida para el desempeño de sus funciones.

http://publications.paho.org • Fax: (301) 206-9789 • Correo electrónico:paho@pmds.com 